|| Print ISSN: 2589-7837 || Online ISSN: 2581-3935 ||

International Journal of Medical Science and Diagnosis Research (IJMSDR)

Available Online at www.ijmsdr.com

NLM (National Library of Medicine ID: 101738824)

Original Research Article

Volume 6, Issue 1; January: 2022; Page No. 44-45

\title{
Bipolar Hemi Arthroplasty for Unstable Osteoporotic Inter- Trochanteric Fractures of Femur
}

\author{
Nitin Sanadhya ${ }^{1}$ \\ ${ }^{1}$ Assistant Professor, Department of Orthopaedics, Geetanjali Medical College and \\ Hospital, Udaipur, India.
}

\section{Conflicts of Interest: Nil}

Corresponding author: Nitin Sanadhya

DOI: https://doi.org/10.32553/ijmsdr.v6i1.906

\begin{abstract}
:
Introduction: As the life expectancy of people is increasing, old age population is also increasing and trochanteric fractures with osteoporosis are getting commoner and producing challenge of regaining people there pre operative activity status for which a cemented bipolar arthroplasty was performed as an alternative to osteosynthesis by Dynamic screws . Harris hip score was assesed at various intervals within a year.
\end{abstract}

Materials and Methods: This is a prospective study including 25 cases of unstable intertrochantric fracture (classified according to Evans classification) with osteoporosis treated with cemented bipolar prosthesis assessed

Result: The mean Harris hip Score was 78.86 by the end of one year.

Discussion: The Harris hip score was at satisfactory level post op and improved over the first six weeks, later it stabilzes till one year

Conclusion: The authors believe cemented bipolar hemiarthroplasty is a useful in osterporotic ustable intertrochantric fractures.

Keywords: intertrochantric fractures, bipoar prosthesis, osteoporosis

\section{Introduction:}

In the present world where population of old age people is growing, the incidence of trochanteric fractures is also increasing and fixation of these fractures with traditional compression screw has a high chances of screw cut through and loss of reduction and futher more it increases the morbidity of the patient due to recumbancy and delay in returning to its pre operative status, in these cases cemented bipolar arthroplasty presents promising results.

\section{Materials and Methods}

This prospective study included 25 fresh cases of unstable inter-trochanteric fracture of femur with between $60-90$ years of age presenting to us within a week of sustaining injury. . The study was conducted after ethical committee clearance of the institution. Informed written consent was taken from all the patients. The fracture was classified unstable as per Evan's classification type III, IV, V, Reverse oblique. Patients were excluded from the study if they were having a) polytrauma, e) comorbidity, f) patients with stable fractures,. There were Evan's type III (6 cases), type IV (10 cases), type V (9 cases) \& Reverse oblique type (0 case) respectively. The degree of Osteoporosis was assessed through Singh Index for Osteoporosis. Time interval between injury and surgery was 2 days to $10 \mathrm{~d}$ (average 5 days Cemented bipolar arthroplasty was performed 
with standard posterior approach and patiernt was mobilized 1st post op day and allowed full weight bearing walking with support and assesed at 14 day post operative stitches were removed and further assessment or functional abilities done at 4 weeks , 6weeks , 3 months , 6 months, and 1 year.

\section{Results}

The present study included 25 cases with unstable intertrochantric fractures (male 13, females 12; mean age $68.5 \mathrm{y}$ ). All cases were followed up till the end of one year. No case was lost to follow-up. In the post procedure mean HHS score was 38.34 which subsequently increased up to 78.86 by the end of one year.

Table 1:

\begin{tabular}{|l|l|}
\hline \multirow{2}{*}{ Time Interval } & Harris Hip Score \\
\cline { 2 - 2 } & Mean \pm SD \\
\hline Postoperative & $38.34 \pm 6.55$ \\
\hline 6 week Follow up & $54.60 \pm 8.18$ \\
\hline 3 month Follow up & $73.97 \pm 11.46$ \\
\hline 6 month Follow up & $78.33 \pm 8.70$ \\
\hline 1 year Follow up & $78.86 \pm 8.13$ \\
\hline
\end{tabular}

\section{Discussion}

We have 78.8 Harris hip score obtained for our study group which is comparable to Kumar et al(1), whoalso got similar results, however Huang et al(2) found no difference between osteosynthesis and bipolar arthroplasty in his study. Sahni et al(3) had superior results then us but they have longer follow up to to 2 years .Elmorsy et al (4) had similar results but they have higher rates of complcations and revision surgery this might be due to their longer followup study upto 2 years. Sinno et al had similar results comparable to ours

\section{Conclusion}

The authors believe that cemented bipolar hemiarthroplasty for unstable intertrochanteric fractures with osteoporosis of femur in elderly, does provide early ambulation, good functional outcome, pain free joint with minimal complications without the need for revision surgery. However it limitation of the study is number of cases and duration of follow up.

\section{References}

1. Kumar Gn K, Meena S, Kumar N V, S M, Raj Mk V. Bipolar hemiarthroplasty in unstable intertrochanteric fractures in elderly: a prospective study. J Clin Diagn Res. 2013;7(8):1669-1671.

2. Huang, J., Shi, Y., Pan, W. et al. Bipolar Hemiarthroplasty should not be selected as the primary option for intertrochanteric fractures in elderly patients. Sci Rep 10, 4840 (2020).

3. Sahni G, Kundar R, Gupta A C, Bipolar arthroplasty in highly comminuted intertrochanteric fractures. Indian J Orthop Surg 2017;3(3):234-240.

4. Elmorsy, M. Saied, M. Zaied and M. Hafez, "Primary Bipolar Arthroplasty in Unstable Intertrochanteric Fractures in Elderly," Open Journal of Orthopedics, Vol. 2 No. 1, 2012, pp. 13-17.

5. Sinno K, Sakr M, Girard J, Khatib H. The effectiveness of primary bipolar arthroplasty in treatment of unstable intertrochanteric fractures in elderly patients. N Am J Med Sci. 2010 Dec;2(12):561-8. 